parrhesia $31 \cdot 2019 \cdot 60-84$

\title{
surrationalism after bachelard: michel serres and le nouveau nouvel esprit scientifique
}

massimiliano simons

\section{INTRODUCTION}

The work of Michel Serres, if considered at all, is often presented as a radical break with or criticism of the work of Gaston Bachelard. This is sometimes also endorsed by Serres himself, who in an interview stated:

Yes, I wrote my thesis under Bachelard, but 1 thought privately that the "new scientific spirit" coming into fashion at that time lagged way behind the sciences. ... The model it offered of the sciences could not, for me, pass as contemporary. This new spirit seemed to me quite old. And so, this milieu was not mine. ${ }^{1}$

Bruno Latour, in a similar vein, has described Serres as the anti-Bachelard. ${ }^{2}$ Within this context the project of Bachelard is described as a naive belief in the rationality of science or as a misguided project to purify science from all non-scientific elements. For instance, in his own work, Latour, inspired by Serres, uses Bachelard as the perfect illustration of the paradox of modernity he is attacking:

Gaston Bachelard's dual enterprise-which [...] exaggerates the objectivity of the sciences by dint of breaking with common sense, and symmetri- 
cally exaggerates the objectless power of the imaginary by dint of epistemological breaks-offers the perfect symbol for this impossible crisis, this drawing and quartering. ${ }^{3}$

This image, however, is too simplistic and in fact makes us unable to really appreciate what we can learn from the work of Bachelard today. As Christiane Frémont correctly notes, "from a genuine post-bachelardian one has too hastily made Michel Serres into an anti-bachelardian." 4 A more interesting picture comes forward if one goes beyond such a simple but radical opposition between Bachelard and Serres. Instead one could focus on a few, but essential continuities between both authors.

Precisely by focusing on Serres's interaction with Bachelard in his early work, a core element of the Bachelardian project that is still at work in Serres's philosophy and remains relevant for contemporary discussions will be highlighted. This does not mean that Bachelard and Serres fundamentally agree on many let alone all topics. On the contrary, clear differences must be recognized, for instance how Serres has developed a radically different ontology focused on the role of objects. This paper thus deals most of all with the early Serres, without discussing his more recent positions and his general ontology of quasi-objects in detail. The aim is rather to understand how Serres's break with Bachelard and French epistemology in general was produced by an intimate dialogue with this tradition. ${ }^{5}$

In this paper, the claim is precisely that clear disagreements concerning topics such as rationalism or the role of objects do not contradict a certain methodological continuity between both authors. It is this methodological aspect of Bachelard that, by still being at work in Serres's philosophy, remains relevant today. In the first part, I will discuss the case of Gaston Bachelard, especially his surrationalism and his philosophie du non. Secondly, I will use this reading of Bachelard to shed a new light on the specific criticisms Serres raised against him. The claim is that, instead of abandoning Bachelard's perspective, Serres's criticisms, even when one acknowledges clear discontinuities in content, can be understood as a radicalization of certain methodological elements at work in Bachelard.

\section{THE PHILOSOPHY OF SCIENCE OF GASTON BACHELARD}

There are many different possible attitudes in the philosophy of science. To grasp what is specific to Bachelard's, it is useful to contrast it in a rather schematic way 
to how philosophy of science is traditionally understood. If one refers to historical examples such as Logical Positivism and its attempts to promote verificationism or confirmation theory, philosophy of science seems to be about formulating criteria for how science is a rational process. Bachelard's project is, however, different in several respects. First of all, projects such as Logical Positivism aim to conceptualize a timeless model of science, i.e. a model that would work for any specific moment in science whatsoever. Secondly, their aim is to propose norms for how science should behave rather than how it factually behaves. In this sense the philosopher has the task of dictating to the scientist how to do science.

\subsection{Surrationalism and the primacy of science}

The program that we can find in Bachelard is rather different. Its aim is similar in the sense that it wants to understand scientific practices, but it must be seen as part of a bigger project, namely trying to understand how human rationality works by 'writing the history of the mind. ${ }^{6}$ In fact, in twentieth-century France there was hardly a distinction between philosophy and history of science in the first place. Rather, they have always been intimately related to one another. ${ }^{7}$ Central to philosophy of science in France is the idea that to understand the rationality of science and the functioning of the human mind, one cannot start from the traditional a priori way. One always has to look at the history of the sciences to see the rational movement of thought.

An important reason why such authors as Bachelard follow this approach, must be linked to the foundational crisis in mathematics and the scientific revolutions in physics at the beginning of the $20^{\text {th }}$ century. ${ }^{8}$ For many philosophers these crises showed that the traditional assumption of an atemporal and ultimate foundation for knowledge and rationality was not so self-evident. How can we still be sure that our beliefs are rational if there can be such historical breaks and revolutions even in mathematics or physics? Projects such as Frege's or Russell's Logicism or Husserlian phenomenology can be understood as responses to these crises and attempts to find new firm foundations for all rational beliefs. ${ }^{9}$

Following Castelli Gattinara, one could state that in France a different approach was taken. Rather than trying to look for a firm foundation underneath the dust of scientific revolutions, authors such as Bachelard claimed that rationality was to be found within the revolutionary act itself. Instead of seeing historicity as a problem for rationality, it was seen as the ground for rationality itself: science was rational

$62 \cdot$ massimiliano simons 
not despite its historical shifts, but because of the historical shifts, which were deemed to be rational stages of scientific thinking. ${ }^{10}$ Exactly, the dialectics of the history of science proved the sciences to be rational.

Now, in the case of Bachelard this is argued for in the name of an 'open rationalism' (rationalisme ouvert) or what he calls a surrationalism. ${ }^{11}$ For Bachelard rationalism does not imply that one should start from a number of fixed cognitive categories. The latter he calls a 'closed rationalism,' where the forms thought can take are fixed for eternity and in fact limit the way we can think and do science. One could think of a simple Kantian scheme, where rationality is defined by timeless categories of understanding. An open rationalism, on the other hand, starts from the idea that the act of rationality lies within the overcoming of the categories of thought by creating novel ones, if deemed necessary by the developments of science. Bachelard argues to

place reason inside the crisis, to prove that the function of reason is to provoke crises and that the polemic reason, to which Kant had only attributed a subalternate role, cannot leave the architectonic reason with its contemplations. We should thus gain access to an open Kantianism, a functional Kantianism, a non-Kantianism, in the same way as one speaks of a nonEuclidian geometry. ${ }^{12}$

In this sense, similar to the subversive nature of surrealism, surrationalism aims to break with conservative tendencies to stick with old categories of thinking. Surrationalism precisely creates the room for scientific practices to redefine our cognitive categories. For Bachelard "science instructs reason. Reason has to obey science, a more evolved science, an evolving science."13 Thus we find in Bachelard the distinctive idea of the primacy of science over philosophy: philosophy should not dictate or supervise a normativity of science, but rather learn from the norms internal to the sciences themselves. ${ }^{14}$

Against the closed rationalism of the philosophers, Bachelard aims to mobilize an open rationalism. This openness, however, is not found within traditional philosophical activity, but within the scientific practices. As a consequence, there exists a broader tension between philosophy and science within Bachelard's oeuvre. For him, scientists continually revise their own categories, while philosophers tend to be conservative about them. ${ }^{15}$ Philosophers wrongly try "to apply necessarily finalist and closed philosophy to open scientific thought."16 For Bachelard, 
the sciences never follow the clear-cut and given philosophical categories. Rather they create their own novel categories because "science ordains philosophy by itself." ${ }^{17}$ Or as he states, "[e]very philosophical mind who puts himself in studying science would see how much of contemporary science is philosophical in its core." ${ }^{18}$ Given philosophical categories are in fact never a solution, but always a problem. This is related to Bachelard's idea that the formation of the scientific mind consists in an epistemological rupture with everyday experience:

We believe, in fact, that scientific progress always shows itself in a rupture, in continuous ruptures, between ordinary knowledge and scientific knowledge, as soon as one is faced with an evolved science, a science which, due to the these ruptures themselves, carries the mark of modernity. ${ }^{19}$

This break implies a break with psychologically tempting images about the scientific object, but also with spontaneous philosophical theories about science. "The scientific mind consists precisely in the bracketing of the first philosophy [la philosophie première]. Just as the experimental activity, the philosophy linked to the scientific activity must be nuanced and, as a consequence, be mobile." ${ }^{\circ \circ}$ But traditional philosophy of science does not do this, and therefore "science does not have the philosophy it deserves." ${ }^{21}$ And this is precisely what Bachelard aims to create in his own work, a surrationalism respecting the openness that is active within scientific practices. In this sense, "epistemology must thus be as flexible as science." 22 The implication is that to really grasp what is going on in scientific practices, looking at the history and development of these sciences becomes a necessity.

In this section we have seen that for Bachelard the relation between philosophy and science is mainly described in a negative way: one should follow the sciences and rather than starting from some given philosophical assumptions, but search for the currently adequate philosophical categories within the sciences themselves. The results depend on the specific scientific field under consideration. Which philosophical categories the philosopher ends up with, depends on the field or even the concept in question.

In this sense, the lesson to be drawnis methodological: the concepts must be the product of the historical data, rather than the other way around. In this way it is a plea for a genuine conceptual flexibility in philosophical categories. Moreover, in order to do this the philosopher can rely on the philosophical activity at work

\section{$64 \cdot$ massimiliano simons}


within the sciences themselves. Not only will this allow the philosopher to better understand the historical case studies he or she is examining, but "we believe rather that it is at the level of particular examples that philosophy of science can give us general lessons." ${ }^{23}$

\subsection{Scientific practice and philosophie du non}

At the same time, however, there is a clear normative idea of scientific progress at work in Bachelard's work. One of his central starting points is that within history of science it is always inevitable to make normative judgments from the present perspective. In this respect, Bachelard contrasts the work of the epistemologist with that of the common historian. The historian looks for facts, and accumulates them in his study without making any normative judgment. This model, however, does not work for the history of science, because "it does not take into account the fact that every historian of science is necessarily a historiographer of Truth [de la Vérité]. The events of science are connected in an ever-increasing truth.”24

According to Bachelard, such normativity is necessary and meaningful. He acknowledges that reading the history of science as a teleological process, where historical episodes must be seen as necessary steps or obstacles with the present as their goal, is problematic. But he distinguishes this from the claim that if one wants to do proper historiography of science it is unavoidable to rewrite the history of science from what is presently seen as scientific and what is not. ${ }^{25}$

At the same time, however, there is a clear notion of historical discontinuity about science in Bachelard's oeuvre. This is the famous epistemological rupture mentioned above. This rupture not only implies a break between spontaneous and scientific concepts, but also historical breaks within the sciences themselves. Claiming that the scientific revolutions at the beginning of the $20^{\text {th }}$ century imply a 'new scientific spirit,' Bachelard argues that there exists a radical discontinuity between Newton and Einstein. "One thus cannot correctly say that the Newtonian world prefigures in its main lines the Einsteinian world."26

At first sight the combination of such a normative framework and historical discontinuities seems problematic. How can contemporary scientific categories be relevant to a past with which scientific practices have broken? Both elements, however are not irreconcilable for Bachelard, but precisely imply each other if one understands what scientific progress is all about. In his book Philosophie du non 
(1940) Bachelard argues that historical progress in science is not made in a continuous manner, but rather through breaks. As stated above, it is precisely in these historical shifts that the scientific mind shows its rationality. But the products of these shifts as well have a specific character, that Bachelard tries to capture through his 'philosophie du non.'

For Bachelard, the sciences progress through a model of incorporation: there is a radical shift in scientific revolutions, but one where the previous theories are not completely abandoned, but rather reappraised and translated into particular and approximate cases of the new theories. "The philosophie du non will therefore be not an attitude of refusal, but an attitude of conciliation." ${ }^{27}$ The example he uses is that of non-Euclidean geometry, which never disproved classical Euclidean geometry, but reappraised it as a specific case of a broader framework. "The generalization by the no must include what it denies. In fact, the whole rise of scientific thought in the last century has come from such dialectical generalizations resulting in the incorporation of what one denies." 28 It is in this manner that he speaks of quantum mechanics as a non-Newtonian physics and of his own epistemology as a non-Cartesian epistemology. ${ }^{29}$

The history of science, thus, follows a progressive dialectical movement, which is fundamentally open-ended. The epistemologist must follow and grasp this movement. "The progress is the dynamics itself of scientific culture, and it is this dynamics that the history of science must describe. ${ }^{\prime \circ}$ For Bachelard this results in a distinction between lapsed history (histoire périmée) and sanctioned history (histoire sanctionnée). Since the history of science is not continuous, but cumulative, this implies also the dismissal of certain parts of science. The former is therefore used as a term for these parts of science that, from the contemporary perspective, are excluded as non-science, while the latter refers to those elements that are preserved.

Bachelard thus endorses a specific form of 'presentism. ${ }^{31}$ Such a normative presentism is quite problematic for many contemporary historians of science and will also be heavily criticized by Serres. However, I want to argue that in the light of Bachelard's surrationalism, Serres's critique should not be understood as a radical break with Bachelard, but rather as an internal dispute about this methodological principle: is Bachelard's presentism not in conflict with the very idea of the openness of surrationalism?

$66 \cdot$ massimiliano simons 
But to see why Bachelard endorses this presentism, one must situate it in the light of the other goals of his philosophy. First of all, as stated above, the goal of French epistemologists such as Bachelard is broader than history of science, but implies the writing of a history of the rational mind. The main objective is not just to grasp specific historical facts, but rather the above mentioned surrationalism and the flexibility of the mind. Secondly, for Bachelard there is also a clear pedagogical task present in its philosophy of science. ${ }^{22}$ Describing the struggle of past science with certain epistemological obstacles, such as ordinary experience and naive philosophical theories, is necessary in order to prevent new students of science from possible missteps, confusions and false theories. History of science, for Bachelard, therefore is not only valuable per se, but serves the "formation of the scientific mind." 33 It is therefore also insufficient to write a so-called 'Whiggish' history of science, where the past works teleologically towards the present (let alone see Bachelard's own project as an example of this). Such an approach fails to appreciate how contemporary scientific theories are not self-evident, but imply certain breaks with ordinary experience and spontaneous philosophy.

\section{MICHEL SERRES'S CRITIQUE OF BACHELARD}

In the previous sections we saw how Bachelard conceives of the relationship between science and philosophy. Now that Bachelard's approach has been made clear, we can reexamine the case of Michel Serres and see that the picture of Serres as an anti-Bachelardian has its limits. On the contrary, this reexamination will allow us to stress some interesting continuities at work between the two, hidden beneath the more visible disagreements.

Although relating both authors is not self-evident, there are in fact several similarities to pinpoint. But before going into that, first the question must be raised what precisely is meant with the claim that Bachelard has influenced Serres. This claim might first of all mean that Serres's early philosophy has been greatly shaped by the way philosophy of science was taught in the 1950s. The way philosophy of science was conceived in France at that time was indeed strongly defined by the work of Bachelard. The typical combination of philosophy and history of science, for example, is found in both authors. But also a clearly constructivist perspective can be found in Bachelard as well as in Serres, focusing not on how the scientist passively studies nature, but rather on how (s) he actively intervenes in nature and 'constructs' the phenomena. 
Serres might thus be Bachelardian in a rather indirect way, namely through the intellectual climate or through other French historical epistemologists such as Georges Canguilhem, or even through the work of Louis Althusser and Michel Foucault. ${ }^{34}$ But Bachelard himself in particular played a more prominent role, besides being the reference point within discussions about philosophy of science in France. Serres himself was (a) first of all a direct pupil of him, since Serres "wrote [his] thesis under the direction of Bachelard, on the difference between the Bourbaki algebraic method and that of the classical mathematicians who had gone before." 35 Moreover, (b) Serres discusses Bachelard extensively in his early work, and even in later interviews concerning his philosophical influences. The result is then also that (c) several key concepts were developed in direct dialogue with Bachelard himself. It is for these reasons that it seems warranted to speak of the Bachelardism of Serres.

Besides such simple continuities there are, however, more substantial links in methodology to highlight. For instance, following new developments within physics, Serres develops a non-determinist physics, where the starting point is not order but disorder. ${ }^{36}$ Clearly, this is in fundamental disagreement with how Bachelard understood physics. However, at the same time this can be seen as a next step in the Bachelardian conception of the development of science, namely that of the above philosophie du non. Similar to how Euclidean mathematics became a borderline case of non-Euclidean mathematics, Serres develops a perspective in which the old physics is an exceptional case in a broader framework where disorder is the rule. "Order is not the norm, but is the exception." ${ }^{37}$ Or as Ilya Prigogine and Isabelle Stengers comment on Serres's philosophy: “There are the rare ones in which determinism exists as a limit-state, costly but conceivable, in which extrapolation is possible between the approximate description of any observer and the infinitely precise one of which Leibniz's God is capable." $3^{8}$ The philosophie du non can thus be found in Serres's reading of contemporary history of science as well. Even though Bachelard and Serres clearly disagree on the content, on a methodological level Serres's distinct view on physics can be seen as loyal to the Bachelardian framework.

Even more telling, however, is that not only the philosophie du non, but also Bachelard's surrationalism is recognizable in Serres. To dig up this similarity, let's take a closer look at what Serres is criticizing Bachelard for:

$68 \cdot$ massimiliano simons 
Yes, 1 wrote my thesis under Bachelard, but 1 thought privately that the "new scientific spirit" coming into fashion at that time lagged way behind the sciences. Behind mathematics, because, instead of speaking of algebra, topology, and the theory of sets, it referred to non-Euclidean geometries, not all that new. Likewise, it lagged behind physics, since it never said a word about information theory nor, later, heard the sound of Hiroshima. It also lagged behind logic, and so on. The model it offered of the sciences could not, for me, pass as contemporary. This new spirit seemed to me quite old. And so, this milieu was not mine. ${ }^{39}$

At first sight, it seems that, according to Serres, the whole idea of Bachelard, that in contemporary physics there is a new scientific spirit at work which calls for revisions in philosophy is problematic. Talking about such an epistemological break, as Bachelard tends to do, is not the right approach. But if one looks closely, Serres is not claiming that there have been no shifts at all that call for our philosophical attention. Rather, he seems to claim that Bachelard is lagging behind the newest developments, since in mathematics for instance, "instead of speaking of algebra, topology, and the theory of sets, it referred to non-Euclidean geometries, not all that new." The problem is not that Bachelard claimed that there was an epistemological break, but that he did not see all the breaks, or the newest ones. In a way then, we could say, Serres accuses Bachelard of not being bachelardian enough, of not being loyal enough to his surrationalism.

Taking this surrationalism of Bachelard as a starting point, the three main criticisms of Serres to Bachelard can be reexamined. The first criticism is already hinted at above, namely that Bachelard did not live up to his own standards, because he had not followed the most recent scientific developments that Serres himself witnessed. "I had the chance to witness, in real time, three or four big scientific revolutions: modern mathematics, biochemistry, information theory and, later on, in Silicon Valley, the digital one." 40 Not only does Serres want to open up this epistemological project even further, but he also aims to write about a new new scientific spirit [nouveau nouvel esprit scientifique]. ${ }^{41}$ Serres claims to follow the sciences even more closely, radicalising a flexibility that even Bachelard lacked. Secondly, these new developments in the sciences result in a shifting role for the philosopher, since the new sciences produce their own internal epistemology. Finally, the problem is not only that the philosopher cannot be an epistemologist anymore, but also that by trying to be merely an epistemologist, he or she misses the whole political dimension of science. Epistemologists such as Bachelard failed 
to hear "the sound of Hiroshima" and Serres tries to correct this. Although these three criticisms seem quite radical, they can, however, all be seen in the light of a surrationalist move. In this sense, the claim can be defended that precisely in criticizing the content of Bachelard's project, Serres remains loyal to its methodology.

\subsection{A new new scientific spirit}

As was clear from Serres's description, Bachelard's epistemology is not yet open enough and in the end reduces science to practices that have to wait for an epistemology to speak out their truth. In that sense, Serres's early work consists in a correction of this element within the Bachelardian project. Serres considers himself well-placed and even obliged to describe this new new scientific spirit because his own training came not from philosophers, but "consisted in witnessing-almost participating in-a profound change in this fundamental science" while "the epistemologists didn't follow."

This new new scientific spirit is mainly inspired by information theory, topology and mathematical structuralism. According to Serres it consists in an ontological shift, resulting in a new ontology that will also prove to be fundamental to his later philosophy. ${ }^{43}$ It leads to a worldview where not only humans possess and transmit information, but where this can be generalized to all possible relations and objects:

There is a constant and continuous dialogue between things which form the historical fabric of events and laws, among whom my intervention is exceptional [...] The general informational language is the fundamental and continuous relation between objects. Even before their deciphering, the certainty that it exists induces the certainty that the external world exists, in the mode of a communicating network, of which all the networks I know and could constitute are singular, exceptional cases, approximating to imitate the real world. ${ }^{44}$

Secondly, following the generalization of this ontological claim, Serres also problematizes Bachelard's profound distinction between science and culture, the rational and the imaginary. Inspired by the promises of structuralism, Serres seems to ask: a new method is made possible, one that "excludes nothing; better yet, it attempts to include everything [...] So why would I exclude literature?" 45 Only an a priori distinction can prevent us from making this move, a criterion imposed by

$70 \cdot$ massimiliano simons 
philosophers from the outside. Again, however, it is by simultaneously dismissing the content of Bachelard's point of view, but radicalizing his methodological principle that we get there.

At several moments, Serres portrays himself as the next step in completing Bachelard's work. In the first book in his Hermes series, Serres labels Bachelard as the last of the classical projects in literary criticism and the first of the structuralist ones: "the contemporary idea of critique defines itself relatively easily as a passage to the limit of the Bachelardian incompleteness." ${ }^{46}$ Starting as it does from the opposition between symbolic analyses of images and rationalist studies of truth, Bachelard's double oeuvre is portrayed as the radicalization of this distinction to the moment where it implodes: the symbolic analyses of the most abstracts myths, namely the archetypes of nature (fire, water, earth, air). The study of the imaginary then implies a natural history and the study of science a psychoanalysis of images. "To a false (and original) alchemy correspond true dreams, to a true (and actual) chemistry correspond false images." 47 Bachelard is the first to combine both projects in one philosophy, but they remain irreconcilable.

Very similarly, in his second Hermes book, Serres describes a three stage process: from the subjective-subjective stage of Descartes, through the subjective-objective stage of Bachelard to the objective-objective stage of the new new scientific spirit..$^{8}$ Serres starts from the 'wax' example of Descartes, which is subjectivesubjective for him since both the sender (the wax) and the receiver of information (the cogito) possess no fixed and objective information, but rather information that is unreliable and ever changing for Descartes. For Bachelard, on the other hand, the world is an undetermined realm of complexity and it is the subject that aided by concepts plus a phénoménotechnique imposes a certain rigor and thus reliable information on the object. By purifying it from the subjective images related to color or smell, one makes objectivity possible. However, in the light of the above mentioned ontological shift, the new new scientific spirit goes one step further and is objective-objective, since both the one who studies and that what is being studied can possess, transmit and receive real and reliable information. "The third stage, one must call objective-objective, since it tends to decipher the language that objects apply to objects, by reconstituting, when it is possible, the objective language." 49 This real information is not limited to the rational side, purified from subjective experiences, but rather consists of both primary and secondary qualities in the object as well as in the subject. One returns to the things themselves; a stage where history and physics, culture and science become one. ${ }^{50}$ 
The new new scientific spirit thus results in one method to study science and culture rather than in two separated methods. This leads to the typical Serresian readings of authors such as Jules Verne or Émile Zola, in whose work Serres finds the genesis of contemporary scientific theories such as thermodynamics. It is also in this context that one should understand Serres's suggestion that "the most scientific works, most instructed works of Bachelard, would they be concerned with the poetic elements? Would we find here written, through a method of negation and denial, the prophecies of the new new scientific spirit?" ${ }^{11}$ According to Serres, hidden within the books concerned with the imaginary, Bachelard opens up a perspective that articulates how the material things can impose their information on our minds. Our imagination must therefore not be seen as independent of the world, but rather as part of and in relation to the networks of the world.

However, it is important to note that the claim is not that Zola, for instance, was equally or even better aware of scientific developments than the scientists. Rather, the idea seems to be that one cannot start from a clear distinction between science and culture, but should be as flexible as the texts themselves. Scientific theories and ideas can be developed within literary texts as well. Not because there is a hidden layer of scientificity in these texts, but rather because both are part of one network, that is not fundamentally broken in two..$^{52}$

Neither does this imply some form of radical relativism, where a scientific practice, theory or text is completely similar to mythical, political or cultural texts. This is definitely not Serres's. He would certainly stress the difference between a scientific practice and other practices, but never in a radical, ontological and a priori way. Claiming that science distinguishes itself by a form of rationalism, even an open one, is already imposing a certain philosophical category on science, namely that of rationality. Instead, Serres wants to separate the question of the rationality of the sciences (which is actually rather an answer than a question) from the underlying question of what one could, following Stengers, call the singularity of the sciences: what is the specificity of scientific practices that distinguishes them from other types of practices?53 Referring to the rationality of these practices is a possible answer to this question, but one that cannot be given a priori. Instead, one should follow the sciences, even through myths and literary texts, rather than delineating from beforehand what the limits of the sciences are. ${ }^{54}$ In this sense there is a clear discontinuity with Bachelard, namely by abandoning the whole notion of rationality. Of the surrationalism, it is the sur-, the open movement that remains at work in Serres, while he abandons the rationalism.

$72 \cdot$ massimiliano simons 
It is in this light that one, thirdly, has to understand the radical shift in how to read the history of science. Serres disagrees with the picture sketched above by Bachelard, that there are clear epistemological ruptures that break with the imaginary part of our thinking and that there is a meaningful distinction to make between lapsed history and sanctioned history. Such an a priori imposing a philosophical dichotomy precludes us from following the sciences in their totality. It prevents us, for example, to see 'contemporary' science at work in the work of authors such as Lucretius. In his book on Lucretius, Serres tries exactly to show how his work, often seen as part of lapsed history, has reemerged as relevant for contemporary fluid mechanics. "Scientific modernity does not enter history by a fault or a break, but by the revival of a philosophy of nature that has been spreading ever since Antiquity. The so-called break is an artefact of the university." 55

The new new scientific spirit thus results in an alternative epistemology of science, which could be called the model of proliferation. Although we will not go into details, the central idea is that the objectivity and rationality of science is strengthened if it is linked to more elements and connections. Elements of literature and imagination can thus play a positive role in the production of knowledge. This is opposed to the model of purification, ascribed to Bachelard, where science becomes more objective if it is purified from imagination and epistemological obstacles.

But there is an ambiguity here, in the case of Serres. He characterizes science which follows the model of purification as repressive of an original multiplicity. "Let this scientific knowledge get rid of its arrogance, its masterly, its ecclesial dispensation, let it abandon its martial aggressiveness, the hateful pretension of always being right, so that it speaks truth, that it descends, pacified, towards common knowledge." ${ }^{6}$

At the same time, Serres claims that this multiplicity can be adequately articulated in his own model of proliferation. In his book on Lucretius, for instance, Serres claims that modern physics is closed off in laboratories, while the fluid mechanics found in Lucretius works also outside, capable to grasp the multiplicity of the world itself. ${ }^{77}$ His book has indeed been read as "a story in which physics neither represses (through experimentation) nor manipulates nature." ${ }^{8}$ Serres, thus, paradoxically, believes to have found a model that is no model, a model that contrary to all other models does not reduce, repress, push into categories the original multiplicity found in nature. 
But such a belief in a 'model without a model' seems unwarranted. A more plausible view is to acknowledge that all models imply some form of violence towards their objects, but not all in the same way. The model of purification, thus, can be criticized for implying a repression of the purified phenomena, but the model of proliferation is itself not free from this violence. It (hopefully) implies less violence or violence of a more acceptable sort. But again, to evaluate this, it is probably necessary to relate the issue to the specific phenomena one is talking about. Serres speaks about whirlpools or climate models. For these phenomena a model of purification seems problematic, indeed. But perhaps Bachelard's model of purification can still be applied to a number of cases, such as quantum mechanics or the theory of relativity. Again, one might mobilize Bachelard's philosophie du non: we can interpret the model of proliferation not as complete dismissal of that of purification, but instead as a model of non-purification, where classical purification remains a limiting case in the broader framework..$^{59}$

\subsection{A new image of the philosopher}

The second crucial element is that the new new scientific spirit also forces Serres to accept a new role of the philosopher. First of all, Serres introduces a new term to describe the philosopher. The model that Serres prefers is that of the encyclopedist, collecting different sciences and types of knowledge, without reducing them or forcing them in a strict hierarchy. Rather they are situated next to one another, with the everlasting possibility of cross-references. ${ }^{60}$ "Science is, on and for itself, a collection of dictionaries: The Encyclopedia." ${ }^{61}$ In this sense, we should correct our claim that Serres follows the model of the philosophie du non. The model of the encyclopedia is a different, yet radicalized version of the philosophie du non. First of all, in the sense that, although regional rationalisms are clearly also present in Bachelard, in the case of Serres these regional criteria for knowledge and truth are also internally developed by the sciences rather than conceptualized by epistemology (see below). ${ }^{62}$ Secondly, the model of the Encyclopedia starts from a different image than that of conciliation and dialectics. "The new spirit focused itself in a philosophy of no; the new new spirit develops itself in a philosophy of transport: intersection, intervention, interception." "63 Again information theory is the paradigm here, for instance in the case of molecular biology. What molecular biologists show is that in genetics one should not search for the 'noumena' underlying our biological beings, the invisible behind the visible, but rather the universality of the genetic code. ${ }^{64}$ Notions from information theory are thus translated, and at the same time transformed, when applied to a different scientific region,

\section{$74 \cdot$ massimiliano simons}


in this case biology.

The encyclopedist, moreover, is not just the Bachelardian epistemologist updated by insights from the contemporary sciences. There is a second and more important revision at work, namely that the newest developments within the sciences have also resulted in a qualitative shift in the sciences themselves, problematizing this traditional image of the epistemologist. Serres radicalizes Bachelard's claim that the sciences themselves produce philosophical categories, by claiming that they now also produce their own epistemology. Serres characterizes these new mature sciences as autoregulative or "autonormée[s]." ${ }^{5}$ Serres makes this claim first of all for mathematics:

At all moments of grand systematic reconstruction, the mathematicians become the epistemologists of their own knowledge. This transformation is a mutation that is carried out from the inside out. Everything happens as if, at the moment of promoting itself into a new system, mathematics suddenly needed to import the totality of epistemological questions. ${ }^{66}$

In other passages he makes similar remarks about contemporary physics, for instance about the work of Léon Brillouin, Science and information theory (1956). "The philosophers do not have to search nor write a manual where one would find the epistemology of the experimental knowledge. It is there." ${ }^{67}$ This has crucial consequences for the task of the philosopher. The idea is that, even if the traditional epistemological project succeeds and one is able to describe the scientific practice in a genuine way, one would only be repeating the sciences themselves. If so, in what sense, then, does the "philosopher's work differ from that of a journalistic chronicler, who announces and comments on the news?" 68 Or more precisely, the philosopher is confronted with a fundamental choice, which Serres at one moment compares to literary criticism. The literary critic either can choose to describe the text as loyally as possible, but he will end up in a philological exercise that will not really add anything significant; or else he tries to be more speculative, but he loses himself in an uncertain art of describing, linked to a certain normative framework. So either the epistemologist merely repeats the sciences or he becomes speculative, in that case implying a tension with the original idea of the primacy of science ${ }^{69}$ Here already it is clear that it is precisely by pushing the traditional Bachelardian project to its boundaries that Serres arrives at one of his fundamental differences with Bachelard: if one would really take the surrationalism of Bachelard seriously, than one can no longer unproblematically write the 
books Bachelard wrote.

\subsection{From an epistemology to a political philosophy}

However, Serres does not chooses to give up all speculative ambition, but rather the opposite. One can never escape the speculative element, and it is therefore necessary to be explicit about it. For Serres, this means opening up for the political side of science as well. An encyclopedist would only add something to the internal epistemology of the sciences if he or she would speak of more than mere epistemology. "To speak the truth, my interest in the relations between science and society marked at the same time my difficulties with philosophy, and, most of all, with Canguilhem and Bachelard. They were out of their time. How could one teach epistemology of physics while omitting deontology?"70 Serres thus goes further than a mere epistemology in the traditional sense, switching to a political project, which aims to correct Bachelard's project by articulating the political violence of the sciences as well. But even this break can be read as playing out Bachelard's own cards against himself: if you really want to pursue an open philosophy, then you must also make room for the political and violent dimensions of science.

It is, however, incorrect if one would interpret this claim as saying that a political project is completely absent in the case of Bachelard, but present in that of Serres. To the contrary, in a famous essay "The Reformation and the Seven Sins" (see this issue) Serres argues that in Bachelard's oeuvre there was always something like a political project. This project is exactly his presentism, the fact of looking for epistemological obstacles and epistemological breaks. For Serres, the model of purification is not only crippled epistemology but a crypto-normative project as well. It is a normative ideal where true science is seen as that which purifies itself from all the obstacles, from imagination, from myth. The Formation of the scientific mind (1938) of Bachelard is not (only) a description of scientific practice, but a political project of how the scientific city should be arranged, namely one with clear and strong walls against imagination, in favor of a spiritual purification of the scientist. Against this Serres states that "a totally purified reason is a myth" and that in fact "there is no purer myth than the idea of a science purified from all myth." "1 Exactly at this point, and once again, the model of proliferation will have to be introduced: it is through the creation of relations, not their destruction, that science comes about.

$76 \cdot$ massimiliano simons 
Does this mean that philosophers should give up normative ambitions completely according to Serres? Although it might seem so, this is not a necessary consequence. Indeed, refraining from giving a distorted reading of his epistemological project, Bachelard himself is not saying that one should use abstract philosophical distinctions to judge the history of science. Not at all, in fact he is claiming that the norms he uses originate in the scientific practices themselves, namely those imposed by the present sciences. Serres's claim is not that one should stop using norms, but rather that one should be wary in what way one bases oneself on certain norms. The problem with Bachelard is not that he judges, but that by judging in his sense, he also endorses a certain political project embodied in the sciences, namely one that makes a distinction between a science that knows and a non-science that does not. It implies a reaffirmation of the political power of the sciences, of Modernity over non-modern elements (suspicions, non-western peoples, religion, etc.). One should - at least analytically—separate within surrationalism the epistemological project (the sur-) from the political one (the rationalism). One should be aware that one is doing both at the same time.

It is this double project Serres has in mind when he adds that the new scientific spirit of Bachelard not only ignored the scientific developments but also had not "heard the sound of Hiroshima." ${ }^{22}$ Serres is puzzled by the paradox that something as rational as science can lead to something as irrational as the atomic bomb. In this context he makes some very strong claims, such as that "humanity is collectively suicidal" and that we live in a thanatocracy, a government of death. ${ }^{73}$ By these scientific developments, the whole world is in danger, because we are faced with what Serres calls world-objects, objects that span a whole dimension of the world (e.g. ballistic missiles span space; satellites span Earth's rotation; nuclear waste spans time, etc.).74

In the second place, the development of science is also reflected in a trend towards codification and secrecy, resulting in a science where "the foundation of scientific rationality is being destroyed." 75 Since scientific practices are auto-normative, they must be able to control themselves through critical inquiry. By locking up science in secrecy and national interests, one destroys this practice. Or as Serres states:

There is knowledge, but the open possibility of feedback control has decreased sharply, almost towards its final dissolution. However, from the moment there is no longer any control, counter-role, there is no longer any 
rationality. The total of the network of scientific interferences does not have the possibility to control itself; although, that was its proper reason. ${ }^{76}$

In Serres's later work this critique gets further extended to other issues, mainly in two ways. First of all, Serres notices that the nuclear winter is not our only worry, or not even our greatest one. Since Le contrat naturel (1990) the problem of climate change, and in more recent work the one of the Anthropocene have come to the foreground. Much inspired by his ontology and epistemology, he understands these problems as a resistance of objects against our current networks, our current political collective. The social contract has to be replaced by a natural contract:

We so-called developed nations are no longer fighting among ourselves; together we are all turning against the world. Literally a world war, and doubly so, since the whole world, meaning all men, imposes losses on the world, meaning things. We shall thus seek to conclude a peace treaty. ${ }^{77}$

This ecological problem is fundamentally linked with another of Serres's concerns, namely the idea that our current way of doing and describing science is problematic, since it does not acknowledge the role objects play in science and society. The ecological crisis is just the clearest example of how by dividing science and culture, we are unable to account for the political consequences of science. In Statues Serres uses the example of the Challenger accident, the spaceship that exploded and killed all seven passengers. ${ }^{78}$ One could argue that this was a mere accident, but in fact, Serres claims it is no accident, but an essential element of science itself. We could have statistically predicted that such accidents would occur, similar to how we know that driving cars will imply traffic accidents. We accept these sacrifices, and find them necessary in order for our society to function, similar to how in mythical societies we have found it necessary to sacrifice persons for the gods, or select a scapegoat to restore social order. Choosing for our current way of doing science, means accepting these sacrifices. Worse even, we deem them necessary, otherwise our society would fall apart. To do epistemology, philosophy of science, one should also be concerned with this kind of violence in science and seek for a less lethal alternative. What Serres has in mind, then, is a political project: how to respect this open element of Bachelard, but at the same time conceptualize a new politics of science, free from the burden of a conception such as rationalism? Serres believes that this can be done by following the model of proliferation. In this sense, his epistemological model is a political model as

\section{$78 \cdot$ massimiliano simons}


well, but a more explicit one.

\section{CONCLUSION}

This paper has tried to show how the work of Michel Serres must be seen not as an 'epistemological break' with Bachelard, but rather as a specific and critical continuation of certain of its methodological elements. Once again, the claim is not that there are no serious disagreements between both authors. They clearly have a different ontology and notions such as rationalism are differently evaluated. But at the same time Serres's work can be read in line with some of Bachelardian notions such as philosophie du non and surrationalism. To do so, one has to look at Serres's early work, where he tries to develop a new new scientific spirit, updating Bachelard's new scientific spirit. But besides mere epistemological corrections, this also implied a shift in the role of the philosopher, who has to open him- or herself to political issues following from science. These shifts have been quite radical, so much so that Serres's recent work is often quite distinct from what one should associate with Bachelard and the tradition of French historical epistemology. But the claim is that this shift itself was, at least partly, brought about (wittingly or unwittingly) by a certain loyalty to Bachelard's surrationalism. It was precisely due to the insights Serres found in the new new scientific spirit, which opened up room for imagination and culture in science, that he saw the need for a political dimension of philosophy of science.

It is possible to argue that a similar move is also at work in the oeuvre of Latour and Stengers. They agree that it is the scientific field that should decide which distinctions are relevant and which are not, and philosophers "should be as undecided as the various actors we follow as to what technoscience is made of; to do so, every time an inside/outside division is built, we should follow the two sides simultaneously, making up a list, no matter how long and heterogeneous, of all those who do the work." 79 This is Latour's famous dictum of 'follow the actors,' which can be interpreted acroding to the lines of Bachelard's surrationalism. A similar rule can be found in the work of Isabelle Stengers, whe she aims at giving a description of the scientific practices that does not insult the scientists themselves. ${ }^{80}$ Both authors, however, follow Serres in stressing the importance of the political aspect, which remains underdeveloped in Bachelard's work. To explore these aspects, however, a new paper would be required. ${ }^{81}$ Here, simply the possibility of this rereading of their work can be noted. Again, one should not be misled by their claims that they fully break with Bachelard. Rather-through their con- 
nection via Serres-one can see their work as loyal to his legacy.

$80 \cdot$ massimiliano simons 


\section{NOTES}

1. Michel Serres and Bruno Latour, Conversations on science, culture and time. Ann Arbor: Michigan university press, 1995, 11.

2. Bruno Latour, We Have Never Been Modern. Cambridge (Mass.): Harvard University Press, 1993, 93 .

3. Latour, Never Modern, 58-59.

4. Christiane Frémont, « Bachelard et Michel Serres : deux tiers-instruits ? ," Cahiers Gaston

Bachelard, no. 10 (2008) : 79. French citations are translated by the author, unless existing translations have been used.

5. The ontological and even political project at work in Serres's philosophy that he develops more extensively in later work has been discussed in a different article, see Massimiliano Simons, "The Parliament of Things and the Anthropocene: How to Listen to 'Quasi-Objects,"” Techné: Research in Philosophy and Technology 21, no. 2-3 (2017): 150-174.

6. See Cristina Chimisso, Writing the history of the mind: Philosophy and science in France, 1900 to 1960s. Aldershot: Ashgate, 2008.

7. This has to do with the institutional background of philosophy of science in France, as well as with particularities of the philosophy of Auguste Comte, who stressed the necessity of the history of science to understand the functioning of the rational mind. See Cristina Chimisso, Gaston Bachelard: Critic of science and the imagination. London: Routledge, 2001; Chimisso, history of the mind ; and Anastasios Brenner, "Is There a Cultural Barrier Between Historical Epistemology and Analytic Philosophy of Science?" International Studies in the Philosophy of Science 29, no. 2 (2015): 201-14. 8. See Enrico Castelli Gattinara, Les inquiétudes de la raison : épistémologie et histoire en France dans l'entre-deux-guerres. Paris: Vrin, 1998.

9. In fact, even logical positivism can be read in this manner, for instance by rereading the philosophy of science of authors like Rudolf Carnap through a Kantian lens. See Michael Friedman, Reconsidering logical positivism. Cambridge: Cambridge University press, 1999.

10. See Léon Brunschvicg, Les étapes de la philosophie mathématique. Paris: Alcan, 1912.

11. Gaston Bachelard, Le nouvel esprit scientifique, Paris : Alcan, 1934, 175 ; Gaston Bachelard, L'engagement rationaliste. Paris: PUF, 1972.

12. Bachelard, L'engagement, 27-28.

13. Gaston Bachelard, La philosophie du non : Essai d'une philosophie du nouvel esprit scientifique. Paris: PUF, 1940, 144.

14. Massimiliano Simons, "Obligation to Judge or Judging Obligations: The Integration of Philosophy and Science in Francophone Philosophy of Science," in The Past, Present, and Future of Integrated History of Philosophy of Science. Eds. Emily Herring, Kevin Jones, Konstantin Kiprijanov and Laura Sellers. Routledge: London, 2018, forthcoming.

15. Gaston Bachelard, Le rationalisme appliqué. Paris: PUF, 1949, 43.

16. Bachelard, philosophie du non, 2.

17. Bachelard, philosophie du non, 22.

18. Gaston Bachelard, Le matérialisme rationnel. Paris: PUF, 1953, 180.

19. Bachelard, matérialisme rationnel, 207.

20. Gaston Bachelard, L'activité rationaliste de la physique contemporaine. Paris: PUF, 17.

21. Bachelard, matérialisme rationnel, 20.

22. Bachelard, rationalisme appliqué, 10. 
23. Bachelard, matérialisme rationnel, 223.

24. Bachelard, matérialisme rationnel, 86.

25. Bachelard, L'activité rationaliste.

26. Bachelard, nouvel esprit, 46.

27. Bachelard, philosophie du non, 15-16.

28. Bachelard, philosophie du non, 137.

29. See Bachelard, nouvel esprit.

30. Bachelard, L'activité rationaliste, 25.

31. See Laurent Loison, "Forms of Presentism in the History of Science. Rethinking the Project of Historical Epistemology." Studies in History and Philosophy of Science 60 (2016): 29-37.

32. See Chimisso, Bachelard.

33. Gaston Bachelard, La formation de l'esprit scientifique: Contribution à une psychanalyse de la connaissance objective. Paris: Vrin, 1938.

34. For instance, both Canguilhem and Foucault discuss the early work of Serres and vice versa Serres was quite aware of their work. See Georges Canguilhem, Ideology and rationality in the history of the life sciences. Cambridge, MA: MIT press, 1988, 18; Foucault, The Archaeology of Knowledge and The Discourse on Language. Pantheon Books: New York, 1972, 5, 190. Canguilhem was in fact one of his supervisors of his doctoral thesis, but Serres claims that the day of his defense was also the day both authors broke with one another. See Michel Serres, Pantopie ou le monde de Michel Serres, de Hermès à Petite Poucette. Paris : Le Pommier, 2016, 49. In the case of Foucault, Serres describes himself as "pupil and colleague." See Serres and Latour, Conversations, 38.

35. Serres and Latour, Conversations, 10.

36. See Ilya Prigogine and Isabelle Stengers, Isabelle. Order out of Chaos: Man's New Dialogue with Nature. London: Fontana Paperbacks, 1984.

37. Michel Serres, Hermès III. La traduction. Paris : Éditions de Minuit, 1974, 49.

38. Ilya Prigogine and Isabelle Stengers, Dynamics from Leibniz to Lucretius. In Hermes: Litera-

ture, Science, Philosophy, edited by Josué V. Harari \& David F. Bell. The Johns Hopkins University Press, Baltimore/London, 1982, 150.

39. Serres and Latour, Conversations, 11.

40. Serres, Pantopie, 50.

41. See Michel Serres, Hermès I, La communication. Paris : Éditions de Minuit, 1969 ; Michel

Serres, Hermès II, L'interférence. Paris : Éditions de Minuit, 1972 ; Serres, La traduction.

42. Serres and Latour, Conversations, 11.

43. See Simons, Parliament of Things.

44. Serres, L'interférence, 110.

45. Michel Serres, «Chapter III: Michel Serres,» in: Raoul Mortley. French Philosophers in conversation: Levinas, Schneider, Serres, Irigaray, Le Doeuff, Derrida, ed. Raoul Mortley (London: Routledge, 1991),52.

46. Serres, La communication, 21-22.

47. Serres, La communication, 25n5.

48. Serres, L'interférence, 13.

49. Serres, L'interférence, 94-95.

50. This idea already echoes Serres's later thought where he focuses on the role of 'quasi-objects.' See Simons, Parliament of Things. However, in the Hermes-series this remains embedded in structuralism, which will disappear from the end of the 1970s. From then on Serres is sceptical of the possibility of general metanarratives. In this later work he focuses more on the multiplic-

\section{$82 \cdot$ massimiliano simons}


ity of relationships without clear boundaries, focusing on the role of myths and art. See Michel Serres, Genèse. Paris: Grasset, 1982 and Bruno Latour, "The Enlightenment without the Critique: A Word on Michel Serres' Philosophy," Royal Institute of Philosophy Lecture Series 21 (1987): 8397.. Like other poststructuralists, however, he remains fundamentally influenced by many of its themes. Since, however, his structuralism was not of the linguistic, but of the mathematical side (related to Bourbarki, among others), his position can best be described as a 'mathematical poststructuralism.'

51. Serres, L'interférence, 78.

52. An open question is, even though there is no natural distinction between scientific and other practices, whether such a distinction cannot be a particular societal product. Some societies, perhaps our contemporary one, might be based on such a purifying construction that constructs a certain distinction between science and culture. Such an argument is, in fact, at work in the philosophy of Bruno Latour and Isabelle Stengers. See Latour, Never Modern and Isabelle Stengers, The invention of modern science. Minneapolis: University of Minnesota press, 2000. 53. See Stengers, invention of modern science.

54. Again, an open question here is whether science consists of certain theories, ideas, perspectives or rather certain practices, relations or material settings. The first option seems to be present in the work of Serres, the second in the work of Latour and Stengers. This might have something to do with the starting points of the authors, either in (bio)chemistry focusing on the material practices or in mathematics, starting from a more abstract approach.

55. Michel Serres, The Birth of Physics. Trans. Jack Hawkes. Manchester: Clinamen Press, 2000, 41. 56. Serres, Genèse, 20.

57. Serres, Birth of Physics, 68.

58. Josué Harari and David Bell, "Introduction: Journal à plusieurs voies,» in: Hermes: Literature, Science, Philosophy, ed. Josué Harari and David Bell. The Johns Hopkins University Press, Baltimore/London, 1982, xvi.

59. This perspective is, for example, present in the work of Latour. His "explanatory model allows us instead to integrate the work of purification as a particular case of mediation [i.e. proliferation]. The only difference between the modern and nonmodern conception is therefore breached, since purification is considered as a useful work requiring instruments, institutions and know-how." Latour, Never Modern, 78.

60. Serres, La communication, 70.

61. Serres, L'interférence, 38.

62. Bachelard, rationalisme appliqué, Chapter 7.

63. Serres, L'interférence, 10.

64. Serres, La traduction, 21.

65. Serres, La communication, 71, $189 n 2$.

66. Serres, La communication, 68.

67. Serres, La traduction, 45 .

68. Serres and Latour, Conversations, 15.

69. Serres, La communication, 62.

70. Serres, Pantopie, 160-161.

71. Serres, L'interférence, 210; Serres, La traduction, 259.

72. Serres and Latour, Conversations, 11.

73. Serres, La traduction, 78.

74. Serres, La traduction, 101. 
75. Serres, La traduction, 88.

76. Serres, La traduction, 88. A similar worry is expressed by Stengers. In her case, the problem is how the knowledge economy is locking biomedical knowledge up behind pay walls and bio-industry, thus creating a scientist that is dependent on patents and not on this autonormativity. As a consequence "this quite specific social fabric will be destroyed when scientists as practitioners do not depend upon each other any longer, but are tied instead to competing industrial interests. It becomes then a matter of survival to confirm the kind of promises that attracted the appetites of investors, and to produce patentable results." Isabelle Stengers, "Wondering About Materialism," in The Speculative Turn: Continental Materialism and Realism. Eds Levi Bryant, Graham Harman and Nick Srnicek, Melbourne: re.press, 2011, 377.

77. Michel Serres, The natural contract. Ann Arbor: University of Michigan press, 1995, 32. This ecological concern has also been taken up by Bruno Latour. See Bruno Latour, Politics of nature: How to bring the sciences into democracy. Cambridge: Harvard university press, 2004 and Bruno Latour, Facing Gaia: Eight lectures on the new climatic regime. Cambridge: Polity, 2017. The ecological crisis is what Latour calls the "generalized revolts of the means: no entity-whale, river, climate, earthworm, tree, calf, cow, pig, brood-agrees any longer to be treated 'simply as a means' but insists on being treated 'always also as an end." Latour, Politics of nature, 155-156. 78. See Michel Serres, Statues: The Second Book of Foundations. Trans. Randolph Burks. Bloomsbury Academic: London, 2014.

79. Bruno Latour, Science in action: how to follow scientists and engineers through society. Cambridge (Mass.): Harvard university press, 1987, 176.

80. Isabelle Stengers, La vierge et le neutrino : les scientifiques dans la tourmente. Paris : Seuil, 2006. 81. But see Simons, Parliament of Things.

\section{$84 \cdot$ massimiliano simons}

